\title{
Ectodomain Shedding of RAGE and TLR4 as a Negative Feedback Regulation in High- Mobility Group Box 1-Activated Aortic Endothelial Cells
}

\author{
Won Seok Yang ${ }^{a} \quad$ Jin Ju Kimb ${ }^{b}$ Mee Jeong Lee ${ }^{c}$ Eun Kyoung Lee \\ Su-Kil Park ${ }^{a}$ \\ aDivision of Nephrology, Department of Internal Medicine, Asan Medical Center, University of Ulsan \\ College of Medicine, Seoul, bAsan Institute for Life Sciences, Seoul, 'Department of Pediatrics, Dankook \\ University College of Medicine, Cheonan, dDivision of Nephrology, Department of Internal Medicine, \\ Dankook University College of Medicine, Cheonan, Korea
}

\section{Key Words}

A disintegrin and metalloprotease 17 - Ectodomain shedding - High-mobility group box 1 • Receptors for advanced glycation end products $\bullet$ Toll-like receptor 4

\begin{abstract}
Background/Aims: High-mobility group box 1 (HMGB1) elicits inflammatory responses through interactions with the receptor for advanced glycation end products (RAGE) and tolllike receptor 4 (TLR4). We investigated how RAGE and TLR4 expressions are regulated after HMGB1 stimulation in cultured human aortic endothelial cells (HAECs). Methods: RAGE and TLR4 expressions were analyzed by Western blot analysis and immunofluorescence staining. A disintegrin and metalloprotease 17 (ADAM17) activity was measured using a fluorogenic substrate. Results: Upon treatment with HMGB1, both RAGE and TLR4 began to decrease in cell lysate and remained decreased up to $24 \mathrm{~h}$. The decrease in cellular RAGE and TLR4 was accompanied by an increase of N-terminal fragment of RAGE and TLR4 in culture supernatant, indicating ectodomain shedding of the receptors. HMGB1 activated p38 mitogen-activated protein kinase (p38 MAPK) and ADAM17, while HMGB1-induced ADAM17 activation was inhibited by SB203580, a p38 MAPK inhibitor. HMGB1-induced ectodomain shedding of RAGE and TLR4 was prevented by siRNA depletion of ADAM17 as well as TAPI-2, an inhibitor of ADAM family, and SB203580. HMGB1 pretreatment abolished p38 MAPK activation in response to 2nd HMGB1 stimulation. In the cells depleted of ADAM17, HMGB1-induced p38 MAPK activation was prolonged. siRNA depletion of RAGE, but not TLR4, suppressed HMGB1induced p38 MAPK activation. Conclusion: In response to HMGB1 stimulation, HAECs rapidly undergo ectodomain shedding of RAGE and TLR4, and thereby become insensitive to further HMGB1 stimulation. ADAM17, activated through RAGE-p38 MAPK pathway, is implicated in the ectodomain cleavage of the receptors.




\section{Cellular Physiology Cell Physiol Biochem 2018;51:1632-1644

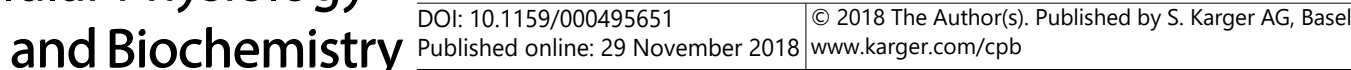 \\ Yang et al.: HMGB1-Induced Ectodomain Shedding of RAGE and TLR4}

\section{Introduction}

High-mobility group box 1 (HMGB1) is a protein in the nucleus where it organizes DNA and regulates gene transcription [1]. In the presence of tissue injury, microbial invasion or oxidative stress, however, HMGB1 translocates to the cytoplasm and then into the extracellular space [1-3]. Once released into the extracellular space, HMGB1 binds to several different receptors on the cell surface and induces sterile inflammation by stimulating the synthesis and release of inflammatory cytokines [4]. The receptor for advanced glycation end products (RAGE) and toll-like receptor 4 (TLR4) are the main receptors for HMGB1 [5]. Clinically, HMGB1 is implicated in the pathogenesis of chronic inflammatory diseases such as atherosclerosis, systemic lupus erythematosus and rheumatoid arthritis as well as sepsis $[1,6]$.

Lipopolysaccharide (LPS) is also an agonist of TLR4. Macrophages stimulated by LPS produce inflammatory cytokines, but on the other hand decrease TLR4 on the cell surface by endocytosis [7] and become less responsive to subsequent LPS exposure. Likewise, HMGB1 was shown to decrease cell surface TLR4 in macrophages by inducing endocytosis $[8,9]$. With regard to RAGE expression following HMGB1 stimulation, the published findings are conflicting. In human microvascular endothelial cells [10] and umbilical vein endothelial cells [11], HMGB1 was shown to increase RAGE expression. In HeLa cells transfected with RAGE [12], HMGB1 stimulation promoted ectodomain shedding of RAGE. In a study of human embryonic kidney cells [13], however, HMGB1 did not induce ectodomain shedding of RAGE.

Recently, we found that human aortic endothelial cells (HAECs) activated by LPS rapidly reduce TLR4 expression, and thereby decrease the responsiveness of the cells to $2^{\text {nd }}$ stimulation with LPS [14]. In contrast to macrophages, however, the loss of cell surface TLR4 in HAECs occurred through ectodomain shedding, but not by endocytosis. Thus, the mechanism by which cells regulate surface receptor expression after its ligand binding seems to be different depending on the type of cells.

Plasma level of HMGB1 is elevated in the patients with diabetes mellitus [15], chronic inflammatory diseases such as systemic lupus erythematosus and rheumatoid arthritis $[16,17]$ or sepsis [18]. In vitro studies have shown that HMGB1 activates aortic endothelial cells, increasing the expression of adhesion molecules and the secretion of TNF- $\alpha$, IL-8 and monocyte chemotactic protein-1 [19]. By these inflammatory effects, HMGB1 is implicated in the pathogenesis of atherosclerosis of aorta and aortic aneurysm $[6,20]$. In case high blood level of HMGB1 is maintained, the severity of its inflammatory effects on aorta may depend on the response of the endothelial cells lining the vessel, but so far it is not known how the cells regulate the response to continuous stimuli of HMGB1.

In the present study, we hypothesized that HAECs may downregulate the receptors for HMGB1 once activated by HMGB1, as in our previous study showing that HAECs undergo ectodomain shedding of TLR4 upon LPS activation [14], and examined the temporal changes of RAGE and TLR4 expression in HAECs after HMGB1 treatment, and investigated the underlying mechanism.

\section{Materials and Methods}

\section{Materials}

Recombinant human HMGB1 (1690-HMB, endotoxin less than $0.10 \mathrm{EU} / \mu \mathrm{g}$ ) was purchased from R\&D Systems (Abingdon, UK). SB203580 and dimethyl sulfoxide (DMSO) were from EMD Chemicals (Darmstadt, Germany). TAPI-2 was from Cayman Chemical (Ann Arbor, MI, USA). Antibodies to human TLR4 (76B357.1: a mouse monoclonal antibody against amino acids 100 - 200 of human TLR4), RAGE (sc-80652, a mouse monoclonal antibody against a truncated extracellular domain of human RAGE), p38 mitogen-activated protein kinase (p38 MAPK), ADAM10 and actin were from Santa Cruz Biotechnology (Santa Cruz, CA, USA). Antibodies to human TLR4 (ab13556; a rabbit polyclonal antibody against amino acids 420-435 of human 


\section{Cellular Physiology Cell Physiol Biochem 2018;51:1632-1644

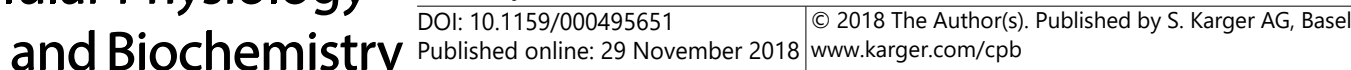

Yang et al.: HMGB1-Induced Ectodomain Shedding of RAGE and TLR4

TLR4) and ADAM17 were from Abcam. An antibody to human phospho-p38 MAPK (Thr180/Tyr182) was from Cell Signaling Technology (Denvers, MA, USA).

ADAM17-siRNA, ADAM10-siRNA, RAGE-siRNA, TLR4-siRNA and control-siRNA (Ambion ${ }^{\circledR}$ ) were from Life Technologies (Paisley, UK). The fluorogenic substrate, 5FAM-Ser-Pro-Leu-Ala-Gln-Ala-Val-Arg-Ser-SerSer-Arg-Lys(5-TAMRA)- $\mathrm{NH}_{2}$, was from Enzo Life Sciences, Inc. (Farmingdale, NY, USA). 4,6-Diamidino-2phenylindole dihydrochloride (DAPI) and Ponceau S solution were from Sigma-Aldrich (St. Louis, MO, USA).

\section{Cell Culture}

Primary HAECs were obtained from Lonza Walkersville, Inc. (Walkersville, MD, USA) and cultured in EBM-2 endothelial growth basal medium (Lonza Walkersville, Inc.). After 3-5 passages, the cells were used for the experiments. In each experiment, the cells were seeded in equal numbers into culture plates and rested in equal volume of M199 Hank's medium (Life Technologies) containing $1 \%$ fetal bovine serum (FBS) for $24 \mathrm{~h}$, and then the medium was replaced with serum-free M199 Hank's medium ( $\left.\mathrm{Ca}^{2+} 1.26 \mathrm{mM}\right)$.

\section{Transfection of SiRNA}

Transfection of siRNAs was performed using Lipofectamine ${ }^{\circledR}$ Reagent (Life Technologies). Briefly, $1 \times 10^{5}$ cells were seeded in each 6-well plate and cultured for $24 \mathrm{~h}$. To prepare siRNA-lipofectamine complexes, siRNAs $(100 \mathrm{pmol})$ were incubated for $15 \mathrm{~min}$ with lipofectamine reagent diluted in Opti$\mathrm{MEM}^{\circledR}$ medium (Life Technologies) at room temperature. siRNAs were transfected by adding the siRNAlipofectamine complexes to the cell in serum-free culture medium and incubating the cells for $6 \mathrm{~h}$ at $37^{\circ} \mathrm{C}$ in a $\mathrm{CO}_{2}$ incubator. After siRNA transfection, the cells were cultured for $18 \mathrm{~h}$ in EBM-2 endothelial growth basal medium. Thereafter, the cells were rested for $24 \mathrm{~h}$ in M199 Hank's medium containing $1 \%$ FBS and then subjected to the experiments.

\section{Western blot analysis}

After collection of the conditioned medium, treated cells were lysed by incubation on ice for $10 \mathrm{~min}$ with cold lysis buffer (50 mM Tris- $\mathrm{HCl}, \mathrm{pH} 7.4,150 \mathrm{mM} \mathrm{NaCl}, 0.25 \%$ sodium deoxycholate, $1 \% \mathrm{NP}-40$, protease and phosphatase inhibitors). The lysed cells were collected using a plastic cell scraper, transferred to a microcentrifuge tube and centrifuged at $4{ }^{\circ} \mathrm{C}(10,000 \times \mathrm{g})$ for $20 \mathrm{~min}$, and the supernatant was obtained as whole cell lysate. The cell lysates containing equal amount of protein were separated under reducing and denaturing condition by sodium dodecyl sulfate-polyacrylamide gel electrophoresis, and transferred to an Immobilon-P membrane (Merck Millipore Co., Darmstadt, Germany). The membrane was then incubated with the primary antibody, followed by washing and further incubation with horseradish peroxidase conjugated secondary antibody. Thereafter, the protein bands were visualized using an enhanced chemiluminescence agent (Luminata ${ }^{\mathrm{TM}}$ Forte Western HRP Substrate; Merck Millipore Co.).

To measure RAGE and TLR4 in culture supernatant, equal volumes of conditioned medium were concentrated 30-fold using Amicon ${ }^{\circledR}$ Ultra $10 \mathrm{~K}$ device (Merck Millipore Co.). The samples were then incubated with $5 \times$ sample buffer for $30 \mathrm{~min}$ at $37^{\circ} \mathrm{C}$ and subjected to immunoblot with a monoclonal antibody against an extracellular domain of RAGE or TLR4. The protein bands on the membrane were stained by Ponceau S Solution.

\section{Immunofluorescence Staining}

Cell surface expression of RAGE and TLR4 was examined by immunofluorescent staining. Treated cells were fixed with $4 \%$ paraformaldehyde for $10 \mathrm{~min}$ without permeabilization, and then incubated with $1 \%$ bovine serum albumin in phosphate buffered saline (PBS) for $60 \mathrm{~min}$ to block the nonspecific binding. Thereafter, the cells were incubated with a mouse monoclonal antibody against an extracellular domain of RAGE or TLR4 overnight at $4{ }^{\circ} \mathrm{C}$, washed with PBS and then further incubated with FITC-conjugated antimouse IgG secondary antibody. Finally, the cells were incubated with DAPI to stain cell nuclei. RAGE or TLR4 immunoreactivity was captured using a confocal microscope (Zeiss LSM710; Carl Zeiss Microscopy, Germany). 


\section{Cellular Physiology Cell Physiol Biochem 2018;51:1632-1644 and Biochemistry DOl: 10.1159/000495651 2018 (0) 2018 The Author(s). Published by S. Karger AG, Basel

\section{Metalloproteinase activity assay}

The metalloproteinase activity assay was performed on cell lysates using 5-FAM-Ser-Pro-LeuAla-Gln-Ala-Val-Arg-Ser-Ser-Ser-Arg-Lys(5-TAMRA)- $\mathrm{NH}_{2}$, a fluorogenic substrate for ADAM17 and other metalloproteinases. This substrate becomes fluorescent upon cleavage of TAMRA group by the metalloproteinases. Whole cell lysates were obtained as in Western blot analysis. The fluorogenic substrate in HBSS buffer $(2 \mu \mathrm{M}, 50 \mu \mathrm{l})$ was added to $50 \mu \mathrm{l}$ of cell lysate $(20 \mu \mathrm{g}$ protein) or cell lysis buffer (for background fluorescence) and incubated at $37^{\circ} \mathrm{C}$ for $60 \mathrm{~min}$. The fluorescent intensity was measured at 485 $\mathrm{nm}$ excitation and $535 \mathrm{~nm}$ emission wavelengths using a fluorescence plate reader (SPECTRmax ${ }^{\circledR}$ GEMINI XS system; Molecular Devices, Sunnyvale, CA, USA). After subtraction of the background fluorescence obtained from the substrate alone (without cell lysate), the fluorescence intensity of the treated cells was expressed as a fold increase compared with that of the control cells.

\section{Statistical Analysis}

Data are presented as means \pm SE (standard error), with $\mathrm{n}$ representing the number of different experiments. An analysis of variance with Scheffe's multiple-comparison test was used to determine statistically significant differences between groups. P values less than 0.05 were considered statistically significant.

\section{Results}

\section{HMGB1 induces ectodomain shedding of RAGE and TLR4}

Because TLR4 rapidly underwent ectodomain shedding in HAECs by stimulation with LPS, a ligand for TLR4, in our previous study [14], we tested whether HMGB1 causes ectodomain shedding of RAGE and TLR4. HAECs were incubated with HMGB1 (100 ng/ $\mathrm{ml}$ ) for up to $24 \mathrm{~h}$, and the conditioned media and whole cell lysates were obtained. RAGE
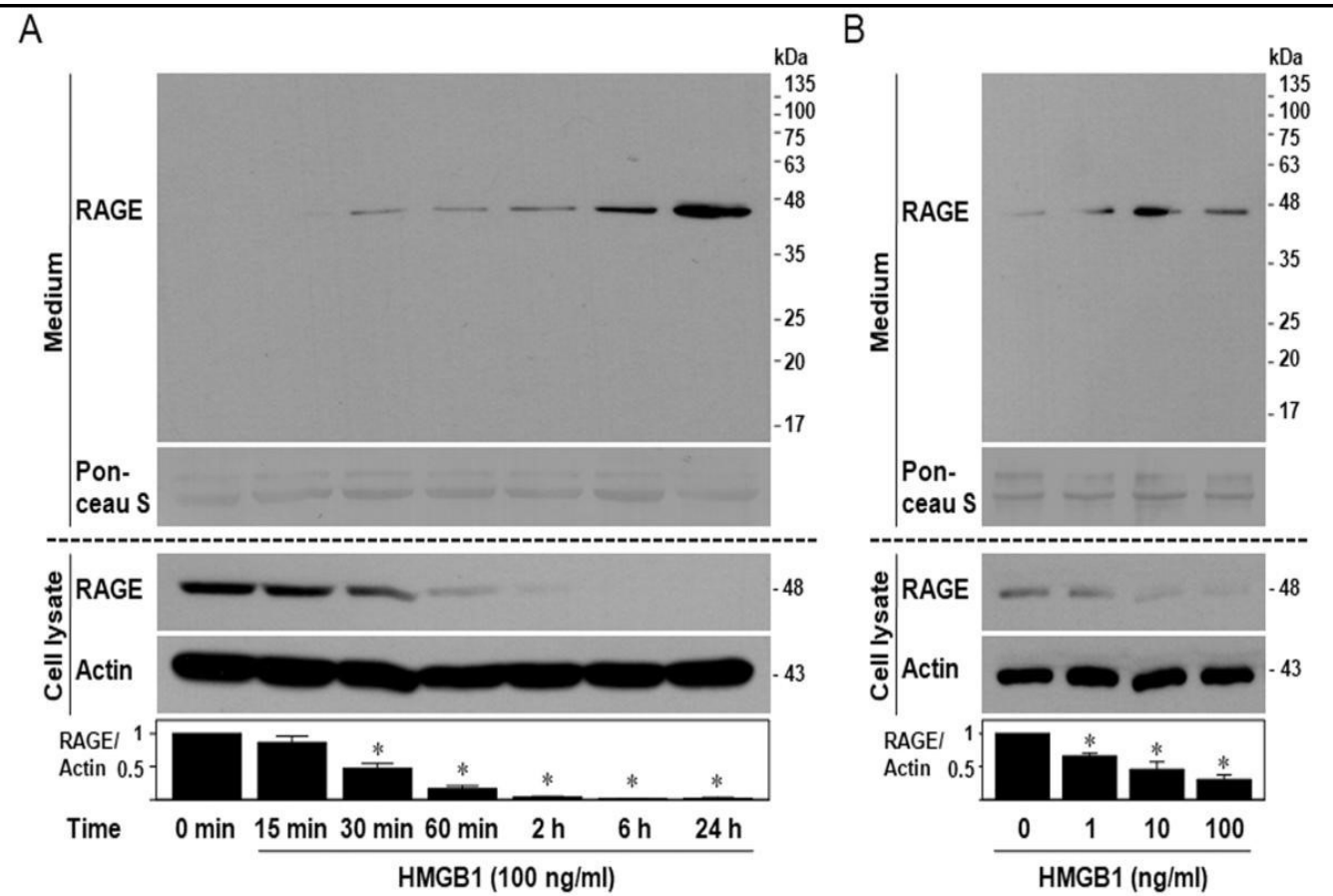

Fig. 1. HMGB1 induces ectodomain shedding of RAGE. (A) HAECs were incubated with HMGB1 (100 ng/ $\mathrm{ml}$ ) for different times (n=4). (B) HAECs were incubated with different concentrations of HMGB1 for $1 \mathrm{~h}$ $(\mathrm{n}=3)$. Cell lysates and culture supernatants were analyzed by Western blotting using anti-RAGE or antiactin antibodies $(* \mathrm{p}<0.05$ compared with control).

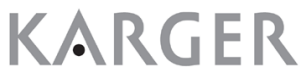




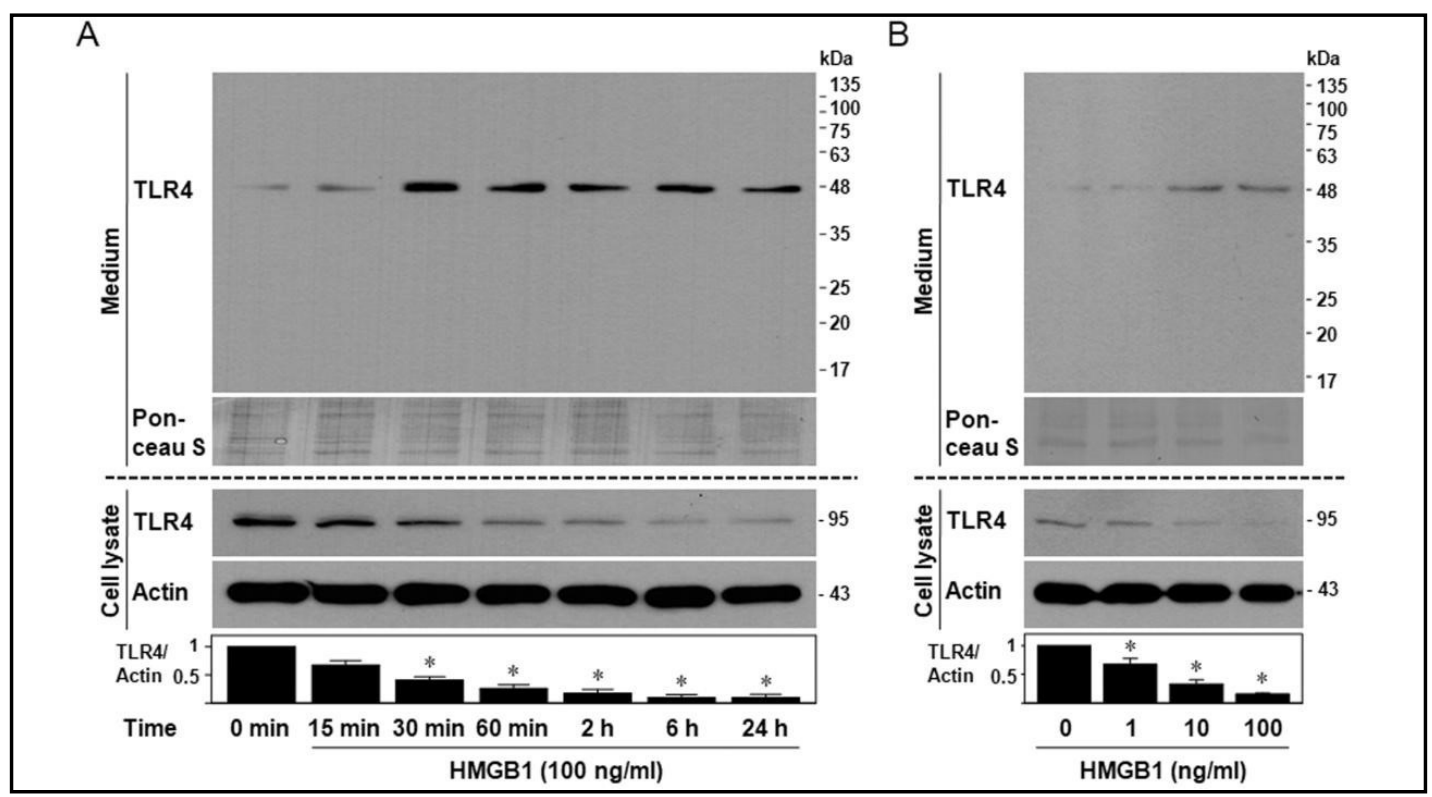

Fig. 2. HMGB1 induces ectodomain shedding of TLR4. (A) HAECs were incubated with HMGB1 (100 ng/ $\mathrm{ml}$ ) for different times (n=4). (B) HAECs were incubated with different concentrations of HMGB1 for $1 \mathrm{~h}$ $(n=5)$. Cell lysates and culture supernatants were analyzed by Western blotting using anti-TLR4 or anti-actin antibodies $\left({ }^{*} \mathrm{p}<0.05\right.$ compared with control).

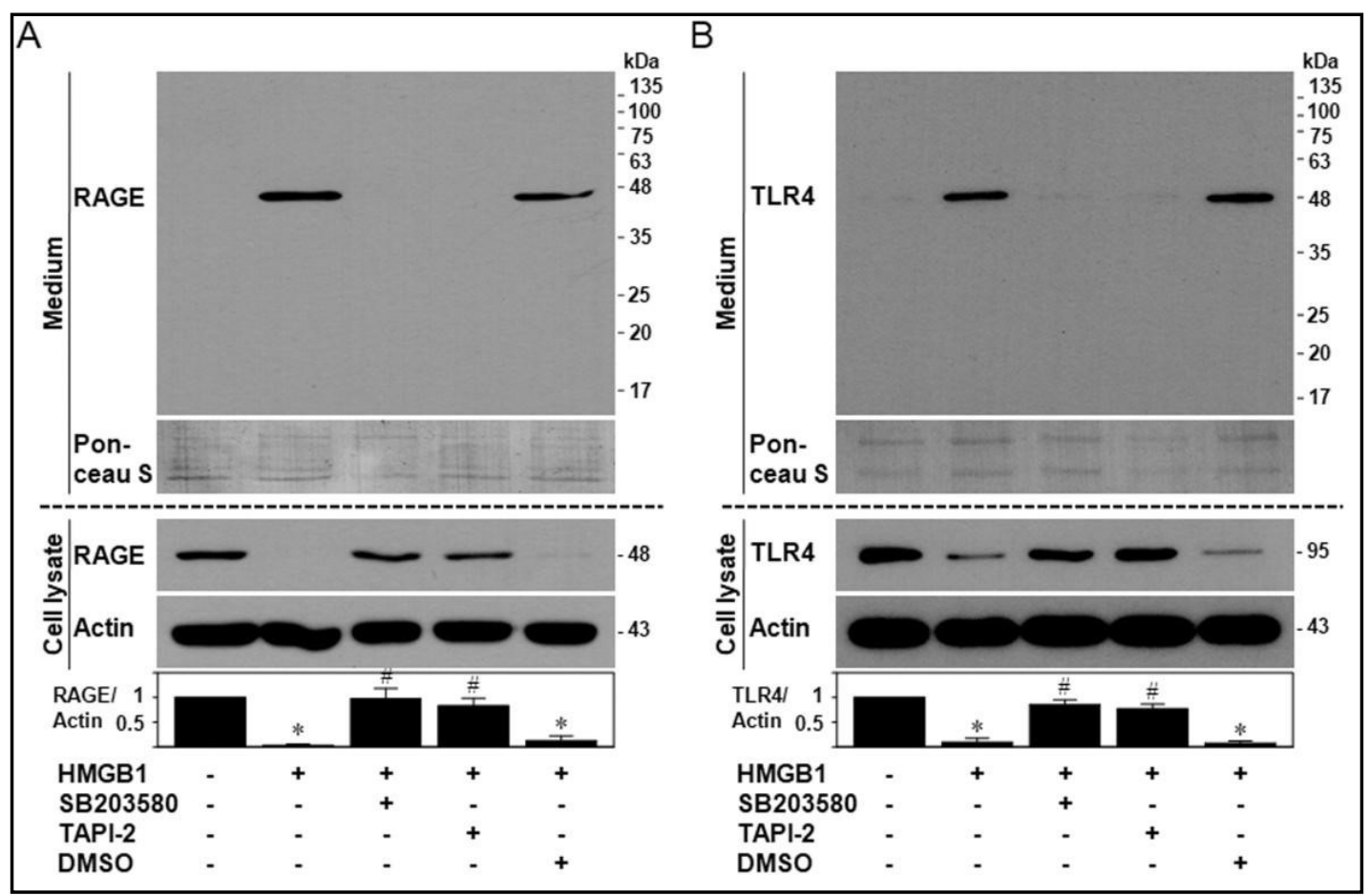

Fig. 3. Involvement of p38 MAPK and metalloproteinase in HMGB1-induced ectodomain shedding of RAGE and TLR4. HAECs were preincubated with SB203580 $(10 \mu \mathrm{M})$, TAPI-2 $(10 \mu \mathrm{M})$ or DMSO (vehicle) for 30 min, followed by incubation with HMGB1 $(100 \mathrm{ng} / \mathrm{ml})$ for $1 \mathrm{~h}$. Cell lysates and culture supernatants were analyzed by Western blotting using anti-RAGE (A), anti-TLR4 (B) or anti-actin antibodies ( $\mathrm{n}=3,{ }^{*} \mathrm{p}<0.05$ compared with control, ${ }^{*} \mathrm{p}<0.05$ compared with HMGB1). 


\section{Cellular Physiology Cell Physiol Biochem 2018;51:1632-1644 and Biochemistry \begin{tabular}{l|l} 
DOI: 10.1159/000495651 & (c) 2018 The Author(s). Published by S. Karger AG, Basel \\
\end{tabular}

and TLR4 in the cell lysates were examined by Western blot analysis. As shown in Fig. 1A \& 2A, cellular RAGE and TLR4 began to decrease within 30 min after HMGB1 treatment and remained decreased up to $24 \mathrm{~h}$. RAGE and TLR4 in the culture supernatants were detected slightly below $48 \mathrm{kDa}$ and at around $48 \mathrm{kDa}$, respectively. The decrease in cellular RAGE and TLR4 after HMGB1 treatment was accompanied by an increase of $\mathrm{N}$-terminal fragment of RAGE and TLR4 in culture supernatant.

HMGB1-induced ectodomain shedding of RAGE and TLR4 was dose-dependent at the concentrations between $1 \sim 100 \mathrm{ng} / \mathrm{ml}$ (Fig. 1B \& 2B).

Involvement of $\mathrm{p} 38$ MAPK and metalloproteinase in HMGB1-induced ectodomain shedding of RAGE and TLR4

To test whether p38 MAPK and metalloproteinase are implicated in HMGB1-induced ectodomain shedding of RAGE and TLR4, we preincubated the cells with or without SB203580 (an inhibitor of p38 MAPK) or TAPI-2 (an inhibitor of ADAM family), and then stimulated them with HMGB1 for 60 min. As shown in Fig. 3, both inhibitors attenuated HMGB1-induced ectodomain shedding of RAGE and TLR4.

HMGB1 induces a marked reduction in the expression of RAGE and TLR4 on the cell surface

Ectodomain shedding of RAGE and TLR4 should result in the reduction of RAGE and TLR4 expression on the plasma membrane. To test whether this is the case, we examined the cell surface expression of RAGE and TLR4 by immunofluorescent staining. HAECs were preincubated with or without SB203580 or TAPI-2, and then stimulated with HMGB1 for 60 min. Thereafter, the cells were immunostained for RAGE and TLR4 using a monoclonal antibody against the extracellular portion of RAGE or TLR4, without permeabilization of the cell membrane. Consistent with Western blot analysis, HMGB1 decreased RAGE and TLR4 expressions on the cell surface, while this effect of HMGB1 was inhibited by SB203580 and TAPI-2 (Fig. 4).

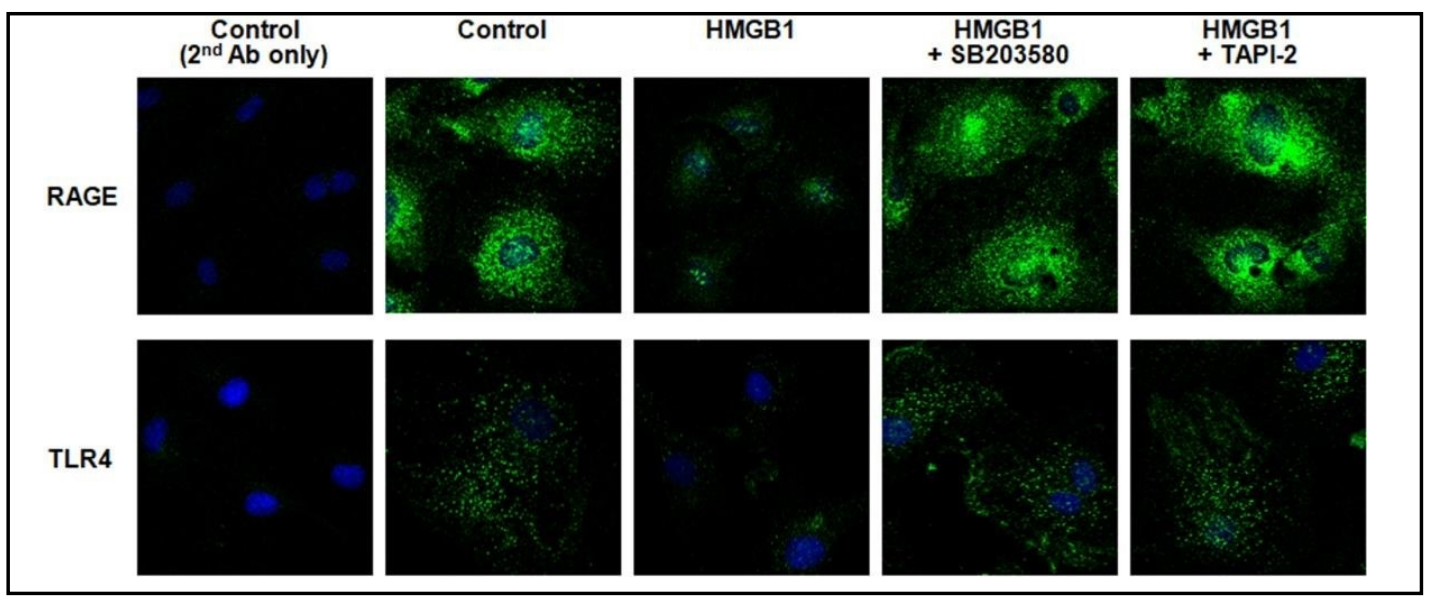

Fig. 4. HMGB1 markedly reduces RAGE and TLR4 on the cell surface. HAECs were preincubated with SB203580 $(10 \mu \mathrm{M})$, TAPI-2 $(10 \mu \mathrm{M})$ or DMSO (vehicle) for $30 \mathrm{~min}$, followed by incubation with or without HMGB1 (100 ng/ml) for $1 \mathrm{~h}$. Thereafter, the cells were fixed with $4 \%$ paraformaldehyde without permeabilization, immunostained for RAGE or TLR4 using a monoclonal antibody directed against the extracellular domain of human RAGE or TLR4, and visualized with confocal microscopy. Cell nuclei were stained with DAPI. Representative images from three independent experiments are shown. 


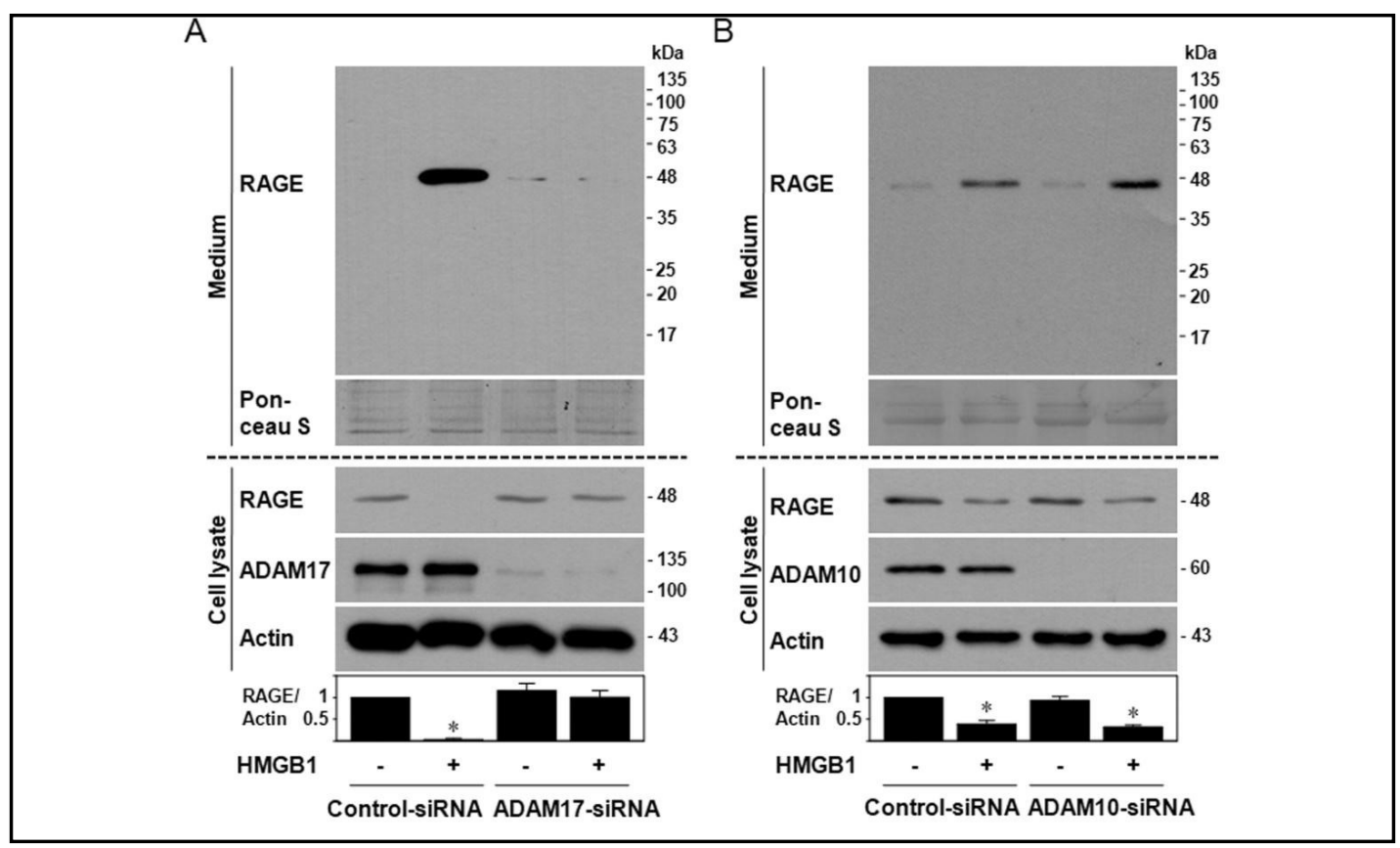

Fig. 5. ADAM17, but not ADAM10, is implicated in the ectodomain shedding of RAGE. HAECs were transfected with control-siRNA, ADAM17-siRNA (A), or ADAM10-siRNA (B) and then incubated with or without HMGB1 (100 ng/ml) for $1 \mathrm{~h}$. Cell lysates and culture supernatants were analyzed by Western blotting using antiRAGE, anti-ADAM17, anti-ADAM10 or anti-actin antibodies ( $\mathrm{n}=3,{ }^{*} \mathrm{p}<0.05$ compared with control).

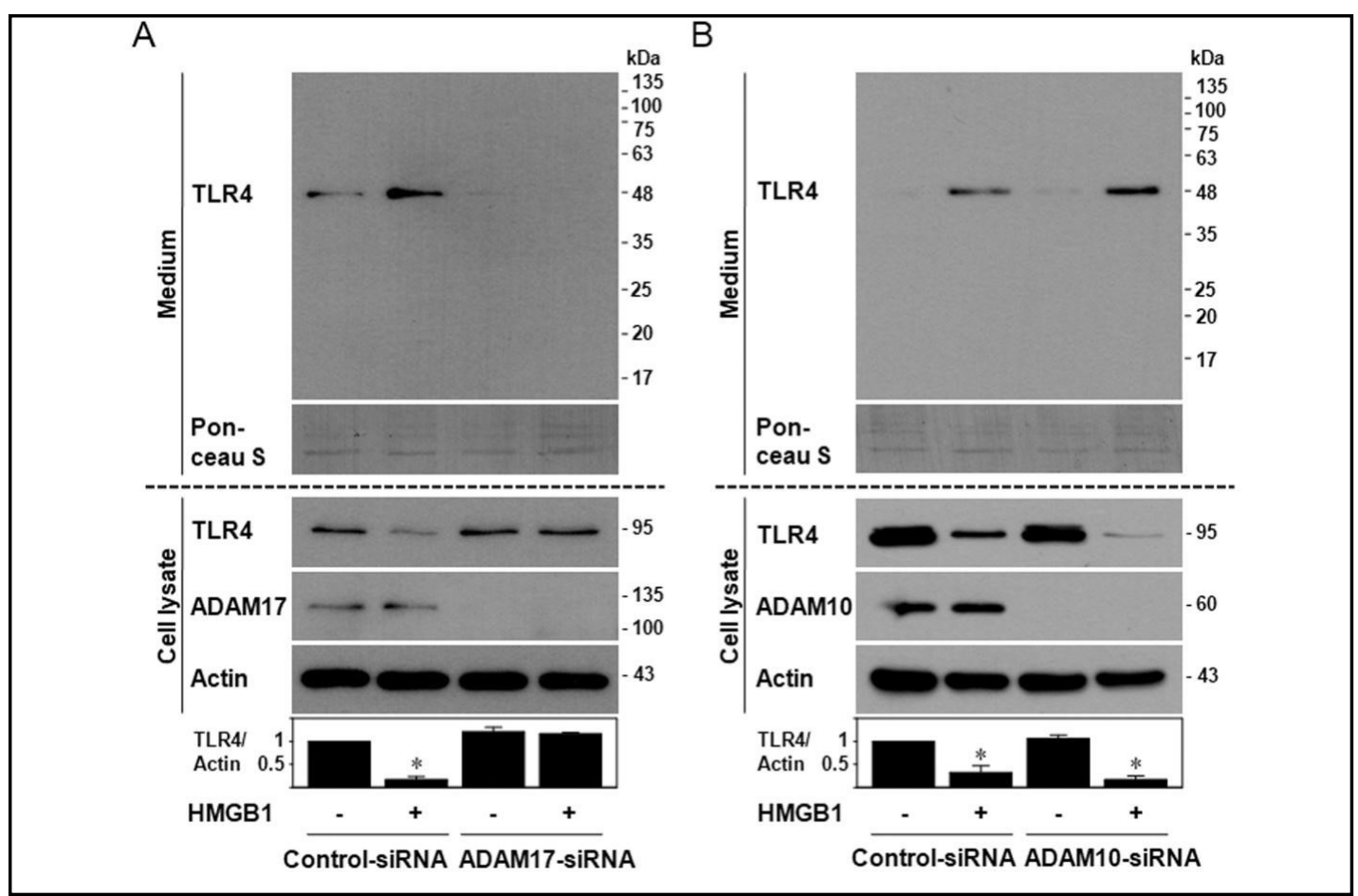

Fig. 6. ADAM17, but not ADAM10, is implicated in the ectodomain shedding of TLR4. HAECs were transfected with control-siRNA, ADAM17-siRNA (A), or ADAM10-siRNA (B) and then incubated with or without HMGB1 $(100 \mathrm{ng} / \mathrm{ml})$ for $1 \mathrm{~h}$. Cell lysates and culture supernatants were analyzed by Western blotting using antiTLR4, anti-ADAM17, anti-ADAM10 or anti-actin antibodies ( $\mathrm{n}=3,{ }^{*} \mathrm{p}<0.05$ compared with control).

\section{KARGER}


ADAM17 is implicated in the ectodomain shedding of RAGE and TLR4

To investigate the effect of specific depletion of ADAM17, we transfected the cells with controlsiRNA or ADAM17-siRNA and then incubated the cells with or without HMGB1. As shown in Fig. 5A \& 6A, depletion of ADAM17 abolished HMGB1-induced ectodomain shedding of RAGE and TLR4. Because ADAM10 is also able to cleave ectodomain portion of RAGE [12, 13, 21] and TLR4 [22], we examined the involvement of ADAM10 in HMGB1-induced ectodomain shedding of RAGE and TLR4. As shown in Fig. 5B \& 6B, HMGB1induced ectodomain shedding of RAGE and TLR4 was not affected by ADAM10 depletion.

\section{HMGB1 activates $p 38$ MAPK}

To determine the temporal changes of p38 MAPK activation after HMGB1 treatment, we treated the cells with HMGB1 $(100 \mathrm{ng} / \mathrm{ml})$ for different times up to 24 h. As shown in Fig. 7, phosphorylation of p38 MAPK was increased after HMGB1 treatment and reached a peak at $60 \mathrm{~min}$, and thereafter decreased.

HMGB1 activates ADAM17 through p38 MAPK pathway

We tested whether HMGB1 activates ADAM17, and whether

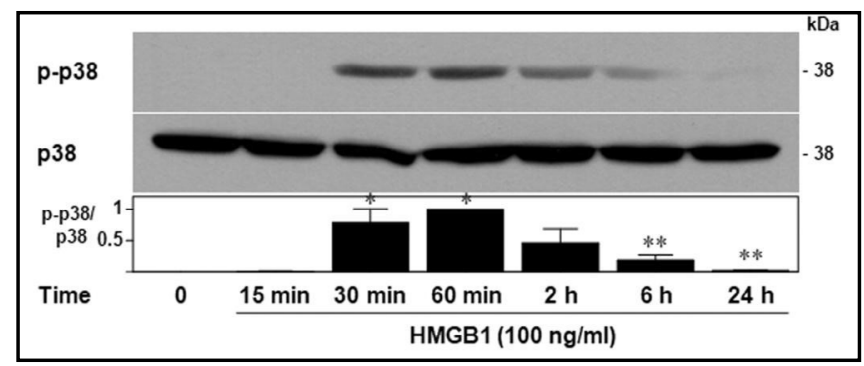

Fig. 7. HMGB1 activates p38 MAPK. HAECs were incubated with HMGB1 (100 ng/ml) for different times as indicated. Whole cell lysates were immunoblotted with an antibody to p-p38 MAPK or p38 MAPK $\left(\mathrm{n}=3,{ }^{*} \mathrm{p}<0.05\right.$ compared with control, ${ }^{* *} \mathrm{p}<0.05$ compared with $60 \mathrm{~min})$.

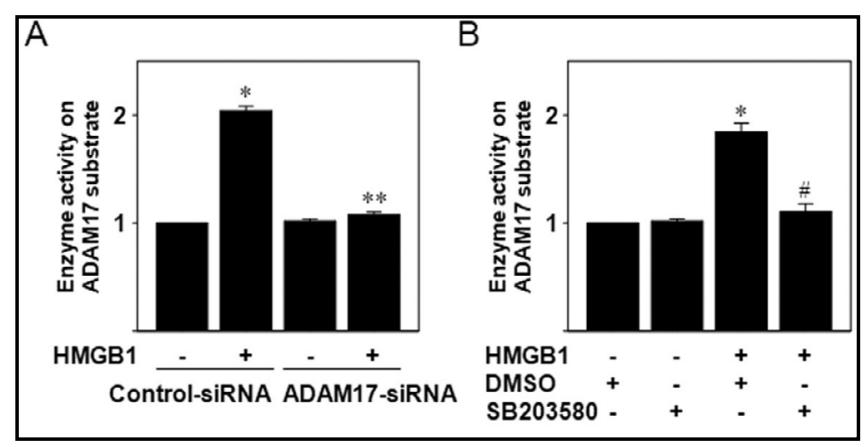

Fig. 8. HMGB1 activates ADAM17 through p38 MAPK pathway. (A) HAECs were transfected with control-siRNA or ADAM17siRNA. Forty-eight hours later, the cells were treated with or without HMGB1 (100 ng/ml) for $1 \mathrm{~h}$. (B) HAECs were preincubated with or without SB203580 $(10 \mu \mathrm{M})$ or DMSO (vehicle) for $30 \mathrm{~min}$, and then further incubated with or without HMGB1 $(100 \mathrm{ng} / \mathrm{ml})$ for $1 \mathrm{~h}$. Cell lysates $(20 \mu \mathrm{g})$ were incubated with a fluorogenic ADAM17 substrate (a final concentration of $1 \mu \mathrm{M}$ ) for $1 \mathrm{~h}$ and fluorescent intensity was measured. Enzyme activity was expressed as relative change in the fluorescence intensity compared with the control ( $\mathrm{n}=5$, duplicated, ${ }^{*} \mathrm{p}<0.05$ compared with control, ${ }^{* *} \mathrm{p}<0.05$ compared with control-siRNA plus HMGB1, "p<0.05 compared with HMGB1 plus DSM0). p38 MAPK is implicated in the activation of ADAM17. ADAM17 activity was estimated by the increase in fluorescence intensity resulted from the enzymatic cleavage of the fluorogenic ADAM17 substrate. Because the substrate is not specific to ADAM17 and may also be cleaved by other ADAMs and matrix metalloproteinases, we first compared HMGB1-induced metalloprotease activity in the control cells and ADAM17-depleted cells. As shown in Fig. 8A, HMGB1 increased the metalloprotease activity about two times more than control. In contrast, siRNA depletion of ADAM17 inhibited the increase of metalloprotease activity by more than 90\%. Thus, the metalloprotease activity increased after HMGB1 treatment mainly represents ADAM17 activity.

To test whether p38 MAPK is implicated in the HMGB1-induced ADAM17 activation, we preincubated the cells with or without SB203580, and stimulated them with HMGB1 for $60 \mathrm{~min}$, and then measured ADAM17 activity in the cell lysates. As shown in Fig. 8B, HMGB1 increased ADAM17 activity, while this effect of HMGB1 was markedly inhibited by pretreatment with SB203580. 
HMGB1 pretreatment abolishes the response to $2^{\text {nd }} H M G B 1$ stimuli, while depletion of ADAM17 potentiates the cellular effect of HMGB1

To assess how the ectodomain shedding of RAGE and TLR4 affects the response to $2^{\text {nd }}$ HMGB1 stimuli, we measured HMGB1-induced p38 MAPK phosphorylation in HMGB1pretreated cells and untreated cells. HMGB1 pretreatment was accomplished by being incubated with HMGB1 for 6 h. As shown in Fig. 9A, HMGB1 markedly increased p38 MAPK phosphorylation in untreated cells, but had no such effect in HMGB1-pretreated cells.

To examine how HMGB1 signaling is affected when ectodomain sheddings of RAGE and TLR4 are prohibited by depletion of ADAM17, we compared the change in p38 MAPK phosphorylation over time after HMGB1 stimulation in the control cells and ADAM17depleted cells. HAECs were transfected with control-siRNA or ADAM17-siRNA, and then incubated with HMGB1 for 1, 6 or $24 \mathrm{~h}$. Western blot revealed similar phosphorylation of p38 MAPK at $1 \mathrm{~h}$ after HMGB1 treatment regardless of ADAM17 depletion. In the control cells, there was a marked decline in phosphorylation of p38 MAPK over time. In the cells depleted of ADAM17, however, phosphorylation of p38 MAPK remained elevated at 6 and 24 h (Fig. 9B).

\section{HMGB1-induced p38 MAPK activation occurs mainly through RAGE, but not TLR4}

Finally, we examined the receptor involved in HMGB1-induced p38 MAPK activation. Cells were depleted of RAGE or TLR4 by siRNA transfection and then stimulated with HMGB1. As shown in Fig. 10, depletion of RAGE abolished HMGB1-induced p38 MAPK and ectodomain shedding of TLR4. In contrast, depletion of TLR4 did not inhibit either HMGB1induced p38 MAPK activation or HMGB1-induced ectodomain shedding of RAGE.

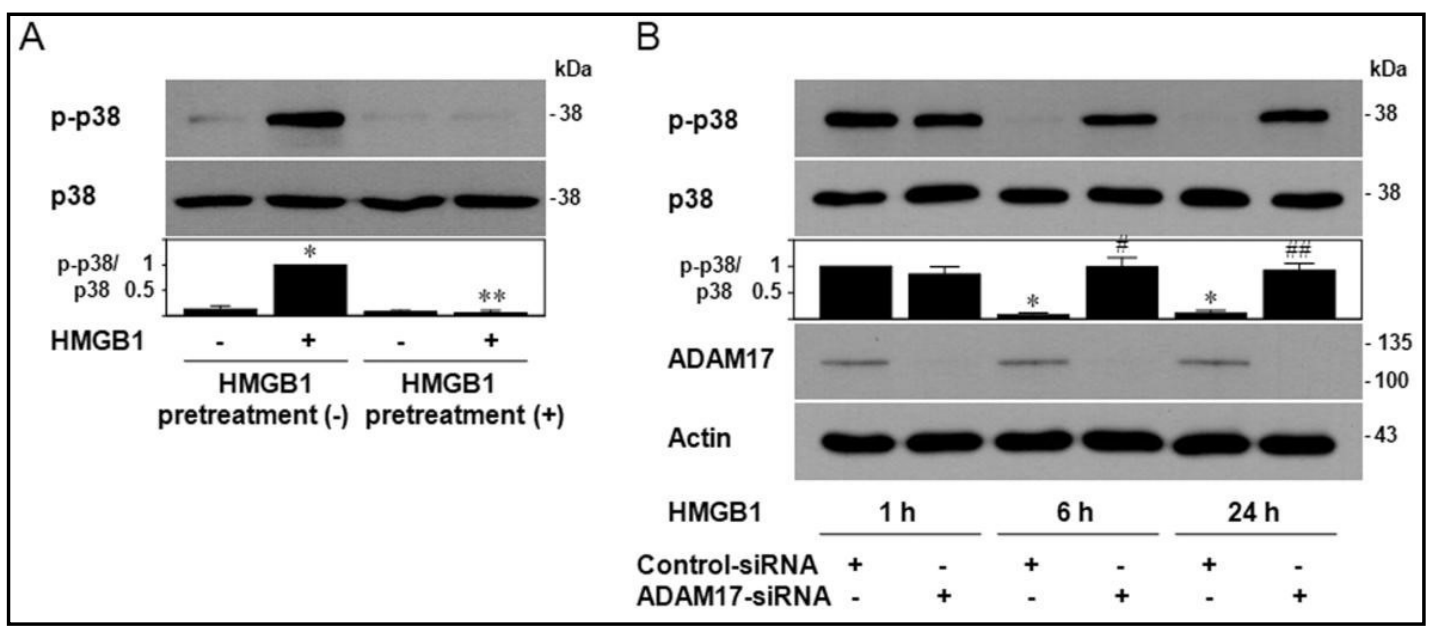

Fig. 9. HMGB1 pretreatment abolishes the response to $2^{\text {nd }}$ HMGB1 stimuli, while depletion of ADAM17 potentiates the cellular effect of HMGB1. (A) HAECs were pretreated with medium alone or HMGB1 (100 $\mathrm{ng} / \mathrm{ml}$ ) for $6 \mathrm{~h}$, washed and then stimulated for $1 \mathrm{~h}$ with HMGB1 $(100 \mathrm{ng} / \mathrm{ml})$. Whole cell lysates were immunoblotted with an antibody to p-p38 MAPK or p38 MAPK ( $\mathrm{n}=4$, * $\mathrm{p}<0.05$ compared with control, ${ }^{* *} \mathrm{p}<0.05$ as compared with HMGB1-stimulated cells that received no pretreatment). (B) HAECs were transfected with control-siRNA or ADAM17-siRNA, and then incubated with HMGB1 (100 ng/ml) for 1, 6 or $24 \mathrm{~h}$. Whole cell lysates were immunoblotted with an antibody to p-p38 MAPK, p38 MAPK, ADAM17 or actin ( $n=3,{ }^{*} \mathrm{p}<0.05$ compared with control-siRNA at $1 \mathrm{~h},{ }^{*} \mathrm{p}<0.05$ as compared with control-siRNA at $6 \mathrm{~h},{ }^{\# \#} \mathrm{p}<0.05$ as compared with control-siRNA at $24 \mathrm{~h}$ ).

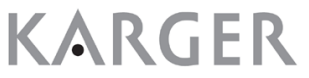


Discussion

The present study demonstrates how HAECs regulate the expressions of RAGE and TLR4 after HMGB1 stimulation. Upon treatment with HMGB1, both RAGE and TLR4 rapidly underwent ectodomain shedding, which resulted in decreased responsiveness of the cells to further stimuli of HMGB1.

In human microvascular endothelial cells [10] and umbilical vein endothelial cells [11], HMGB1 was reported to increase RAGE expression. By contrast, we found that HMGB1 treatment decreases cell surface RAGE and TLR4 in HAECs. The loss of cell surface RAGE and TLR4 was attributed to ectodomain shedding of the receptors, as evidenced by the reduction of RAGE and TLR4 in whole cell lysate with an accompanied increase in $\mathrm{N}$-terminal fragment of RAGE and TLR4 in the culture supernatant. Our finding is consistent with a study showing that HMGB1 promotes ectodomain shedding of RAGE in HeLa cells transfected with RAGE [12]. Ectodomain shedding of RAGE and TLR4 abolished the activation of p38 MAPK in response to $2^{\text {nd }}$ HMGB1 stimulation. Conversely, prevention of ectodomain shedding of RAGE and TLR4 by siRNA depletion of ADAM17 resulted in prolongation of HMGB1 effects on $\mathrm{p} 38$ MAPK activation. The findings together indicate that HMGB1-activated HAECs become insensitive to $2^{\text {nd }}$ stimuli of HMGB1 by ectodomain shedding of the receptors.

HMGB1-induced ectodomain shedding of RAGE and TLR4 was mediated by ADAM17, but not by ADAM10. In our previous studies, 1,25-dihydroxyvitamin $\mathrm{D}_{3}$ activated ADAM10 through extracellular $\mathrm{Ca}^{2+}$ influx [22], while LPS activated ADAM17 through p38 MAPK pathway [14]. Activation of either ADAM10 or ADAM17 led to ectodomain shedding of TLR4. Thus, it is not strange that ADAM17 mediates HMGB1-induced ectodomain shedding of TLR4 because HMGB1 activated p38 MAPK. In case of RAGE, ADAM10, but not ADAM17, has been reported to be the major sheddase $[12,13,21]$. In the present study of HAECs, however, HMGB1 activated ADAM17, while depletion of ADAM17 markedly inhibited HMGB1-induced ectodomain shedding of RAGE. Thus, our data revealed that ADAM17 is also an important sheddase of RAGE.

HMGB1 exists in different forms of redox state and binds to different receptors on the cell surface, depending on the redox status. Within the cells, HMGB1 exists in fully reduced form [23]. After released outside of the cells, fully reduced HMGB1 acts as a ligand to RAGE or the chemokine receptor CXCR4, but does not bind to TLR4 [23]. In the extracellular space, fully reduced HMGB1 may transform into disulfide HMGB1 by formation of a disulfide bond between Cys23 and Cys45. Disulfide HMGB1 signals via TLR4 [23]. By binding to different receptors, HMGB1 has distinct cellular effects according to redox status. HMGB1 binding to RAGE activates mitogen-activated protein kinase pathways and nuclear factor- $\kappa B(N F-\kappa B)$, 


\section{Cellular Physiology Cell Physiol Biochem 2018;51:1632-1644

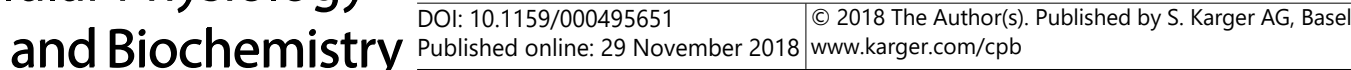 \\ Yang et al.: HMGB1-Induced Ectodomain Shedding of RAGE and TLR4}

and increases the expression of adhesion molecules and the secretion of chemokines [24], while HMGB1 binding to CXCR4 potentiates chemotactic activity [23, 24]. HMGB1 binding to TLR4 activates NF- $\mathrm{KB}$ and increases the transcription and secretion of inflammatory mediators [24]. HMGB1 may also undergo oxidative modifications by reactive oxygen species and lose its immune function [23].

Recombinant HMGB1 used in the present study seems to include both fully reduced HMGB1 and disulfide HMGB1 because its cellular effect was shown to be mediated largely via RAGE in some studies [25, 26], and largely via TLR4 in other studies [27, 28]. In the present study, depletion of RAGE prevented HMGB1-induced p38 MAPK activation and ectodomain shedding of TLR4, while depletion of TLR4 had little effect on HMGB1-induced p38 MAPK activation and ectodomain shedding of RAGE. Thus, RAGE, but not TLR4, was the primary receptor signaling HMGB1-induced ectodomain shedding of RAGE and TLR4 through p38 MAPK and ADAM17 activations. In our previous study [14], LPS stimulated ADAM17-mediated ectodomain shedding of TLR4 through TLR4-p38 MAPK pathway. As HMGB1 is also a TLR4 agonist, TLR4 was anticipated to mediate this effect of HMGB1, but this was not the case. It is similar to endocytosis of TLR4 in macrophage. LPS provokes inflammatory responses of macrophage through TLR4, but also induces endocytosis of TLR4 which desensitizes the cell to $2^{\text {nd }}$ LPS challenge [7]. HMGB1 also induces endocytosis of TLR4 in macrophage, but it was shown to be mediated through RAGE, but not TLR4 [8]. Though both HMGB1 and LPS are agonists of TLR4, other studies have also shown that HMGB1 does not always induce the same cellular effects observed with LPS treatment $[29,30]$. The reason is not clear, but it was assumed that both HMGB1 and LPS activate TLR4 by binding to MD2 , but to separate MD-2 epitopes, and thereby may activate different downstream signaling pathways [30]. It may also be because HMGB1 has lower affinity for TLR4 than LPS [24].

Blood level of HMGB1 is markedly elevated in a variety of diseases. Our findings show how aortic endothelial cells regulate the response to HMGB1 in case high blood level of HMGB1 is maintained. Upon stimulation of HAECs with HMGB1, ADAM17 was also activated and decreased the receptors for HMGB1 by cleaving ectodomain of RAGE and TLR4, and thereby rendered the cells insensitive to further HMGB1 stimulation. It could be a protective mechanism preventing overstimulation from the continuous or repeated exposure to HMGB1. In line with it, ADAM17 was atheroprotective and its deficiency was shown to promote atherosclerosis in mouse models of atherosclerosis [31, 32].

In the present study, HMGB1 was effective at $1 \sim 100 \mathrm{ng} / \mathrm{ml}$ in ectodomain shedding of RAGE and TLR4, dose-dependently. The mean serum level of HMGB1 was reported to be $1.7 \sim 40 \mathrm{ng} / \mathrm{ml}$ in normal subjects, different across the studies [33-35]. In patients with rheumatoid arthritis or systemic lupus erythematosus, HMGB1 was elevated to 71 (45-99) $\mathrm{ng} / \mathrm{ml}$ (median, range) or $108 \pm 48 \mathrm{ng} / \mathrm{ml}$ (mean \pm standard deviation), respectively [17]. In the septic condition, HMGB1 level was shown to be higher than $100 \mathrm{ng} / \mathrm{ml}$ [36]. Thus, the concentrations of HMGB1 tested in the present study are those observed in the clinical setting.

\section{Conclusion}

Upon stimulation with HMGB1, HAECs rapidly undergo ectodomain shedding of RAGE and TLR4, and thereby become insensitive to further HMGB1 stimulation. ADAM17, activated via RAGE-p38 MAPK pathway, is implicated in the ectodomain cleavage of the receptors.

\section{Acknowledgements}

This study was supported by a grant (02-200) from the Asan Institute for Life Sciences (Seoul, Korea). The authors thank Moon Soo Young and Han Nam Jeong for their excellent technical assistance. 


\section{Cellular Physiology Cell Physiol Biochem 2018;51:1632-1644 and Biochemistry \begin{tabular}{l|l} 
DOI: 10.1159/000495651 & (c) 2018 The Author(s). Published by S. Karger AG, Basel \\
www.karger.com/cpb
\end{tabular}

Yang et al.: HMGB1-Induced Ectodomain Shedding of RAGE and TLR4

\section{Disclosure Statement}

No conflict of interests exists.

\section{References}

1 Klune JR, Dhupar R, Cardinal J, Billiar TR, Tsung A: HMGB1: endogenous danger signaling. Mol Med 2008;14:476-484.

-2 Yang WS, Kim JS, Han NJ, Lee MJ, Park SK: Toll-like receptor 4/spleen tyrosine kinase complex in high glucose signal transduction of proximal tubular epithelial cells. Cell Physiol Biochem 2015;35:2309-2319.

-3 Yang WS, Han NJ, Kim JJ, Lee MJ, Park SK: TNF- $\alpha$ activates high-mobility group box 1 - toll-like receptor 4 signaling pathway in human aortic endothelial cells. Cell Physiol Biochem 2016;38:2139-2151.

4 Yanai H, Ban T, Taniguchi T: High-mobility group box family of proteins: ligand and sensor for innate immunity. Trends Immunol 2012;33:633-640.

5 Wu H, Li R, Pei LG, Wei ZH, Kang LN, Wang L, Xie J, Xu B: Emerging role of high mobility group box-1 in thrombosis-related diseases. Cell Physiol Biochem 2018;47:1319-1337.

6 de Souza AW, Westra J, Limburg PC, Bijl M, Kallenberg CG: HMGB1 in vascular diseases: Its role in vascular inflammation and atherosclerosis. Autoimmun Rev 2012;11:909-917.

7 Liaunardy-Jopeace A, Gay NJ: Molecular and cellular regulation of toll-like receptor-4 activity induced by lipopolysaccharide ligands. Front Immunol 2014;5:473.

8 Li Z, Scott MJ, Fan EK, Li Y, Liu J, Xiao G, Li S, Billiar TR, Wilson MA, Jiang Y, Fan J: Tissue damage negatively regulates LPS-induced macrophage necroptosis. Cell Death Differ 2016;23:1428-1447.

-9 Aneja RK, Tsung A, Sjodin H, Gefter JV, Delude RL, Billiar TR, Fink MP: Preconditioning with high mobility group box 1 (HMGB1) induces lipopolysaccharide (LPS) tolerance. J Leukoc Biol 2008;84:1326-1334.

10 Fiuza C, Bustin M, Talwar S, Tropea M, Gerstenberger E, Shelhamer JH, Suffredini AF: Inflammationpromoting activity of HMGB1 on human microvascular endothelial cells. Blood 2003;101:2652-2660.

$>11$ Luan ZG, Zhang H, Yang PT, Ma XC, Zhang C, Guo RX: HMGB1 activates nuclear factor- $\kappa$ B signaling by RAGE and increases the production of TNF- $\alpha$ in human umbilical vein endothelial cells. Immunobiology 2010;215:956-962.

12 Raucci A, Cugusi S, Antonelli A, Barabino SM, Monti L, Bierhaus A, Reiss K, Saftig P, Bianchi ME: A soluble form of the receptor for advanced glycation endproducts (RAGE) is produced by proteolytic cleavage of the membrane-bound form by the sheddase a disintegrin and metalloprotease 10 (ADAM10). FASEB J 2008;22:3716-3727.

13 Galichet A, Weibel M, Heizmann CW: Calcium-regulated intramembrane proteolysis of the RAGE receptor. Biochem Biophys Res Commun 2008;370:1-5.

14 Yang WS, Kim JJ, Lee MJ, Lee EK, Park SK: ADAM17-mediated ectodomain shedding of toll-like receptor 4 as a negative feedback regulation in lipopolysaccharide-activated aortic endothelial cells. Cell Physiol Biochem 2018;45:1851-1862.

15 Wang H, Qu H, Deng H: Plasma HMGB-1 levels in subjects with obesity and type 2 diabetes: a crosssectional study in China. PLoS One 2015;10:e0136564.

-16 Abdulahad DA, Westra J, Bijzet J, Limburg PC, Kallenberg CG, Bijl M: High mobility group box 1 (HMGB1) and anti-HMGB1 antibodies and their relation to disease characteristics in systemic lupus erythematosus. Arthritis Res Ther 2011;13:R71.

17 Dyer KD, Rosenberg HF: Physiologic concentrations of HMGB1 have no impact on cytokine-mediated eosinophil survival or chemotaxis in response to Eotaxin-2 (CCL24). PLoS One 2015;10:e0118887.

18 van Zoelen MA, Laterre PF, van Veen SQ, van Till JW, Wittebole X, Bresser P, Tanck MW, Dugernier T, Ishizaka A, Boermeester MA, van der Poll T: Systemic and local high mobility group box 1 concentrations during severe infection. Crit Care Med 2007;35:2799-2804.

19 Bongoni AK, Klymiuk N, Wolf E, Ayares D, Rieben R, Cowan PJ: Transgenic expression of human thrombomodulin inhibits HMGB1-induced porcine aortic endothelial cell activation. Transplantation 2016;100:1871-1879. 


\section{Cellular Physiology Cell Physiol Biochem 2018;51:1632-1644 and Biochemistry \begin{tabular}{l|l} 
DOI: 10.1159/000495651 2018 The Author(s). Published by S. Karger AG, Basel \\
(c)
\end{tabular}

20 Kohno T, Anzai T, Kaneko H, Sugano Y, Shimizu H, Shimoda M, Miyasho T, Okamoto M, Yokota H, Yamada S, Yoshikawa T, Okada Y, Yozu R, Ogawa S, Fukuda K: High-mobility group box 1 protein blockade suppresses development of abdominal aortic aneurysm. J Cardiol 2012;59:299-306.

21 Braley A, Kwak T, Jules J, Harja E, Landgraf R, Hudson BI: Regulation of receptor for advanced glycation end products (RAGE) ectodomain shedding and its role in cell function. J Biol Chem 2016;291:12057-12073.

22 Yang WS, Kim JJ, Han NJ, Lee EK, Park SK: 1,25-Dihydroxyvitamin D $_{3}$ attenuates the effects of lipopolysaccharide by causing ADAM10-dependent ectodomain shedding of toll-like receptor 4. Cell Physiol Biochem 2017;41:2104-2116.

-23 Agalave NM, Svensson CI: Extracellular high-mobility group box 1 protein (HMGB1) as a mediator of persistent pain. Mol Med 2015;20:569-578.

-24 Bianchi ME, Crippa MP, Manfredi AA, Mezzapelle R, Rovere Querini P, Venereau E: High-mobility group box 1 protein orchestrates responses to tissue damage via inflammation, innate and adaptive immunity, and tissue repair. Immunol Rev 2017;280:74-82.

25 Shang D, Peng T, Gou S, Li Y, Wu H, Wang C, Yang Z: High mobility group box protein 1 boosts endothelial albumin transcytosis through the RAGE/Src/caveolin-1 pathway. Sci Rep 2016;6:32180.

-26 Chen Q Bei JJ, Liu C, Feng SB, Zhao WB, Zhou Z, Yu ZP, Du XJ, Hu HY: HMGB1 induces secretion of matrix vesicles by macrophages to enhance ectopic mineralization. PLoS One 2016;11:e0156686.

27 Park SY, Lee SW, Kim HY, Lee WS, Hong KW, Kim CD: HMGB1 induces angiogenesis in rheumatoid arthritis via HIF-1 $\alpha$ activation. Eur J Immunol 2015;45:1216-1227.

28 Deng H, Wang C, Chang DY, Hu N, Chen M, Zhao MH: High mobility group box1 contributes to antimyeloperoxidase antibody-induced glomerular endothelial cell injury through a moesin-dependent route. Arthritis Res Ther 2017;19:125.

29 Silva E, Arcaroli J, He Q Svetkauskaite D, Coldren C, Nick JA, Poch K, Park JS, Banerjee A, Abraham E: HMGB1 and LPS induce distinct patterns of gene expression and activation in neutrophils from patients with sepsis-induced acute lung injury. Intensive Care Med 2007;33:1829-1839.

-30 Li Z, Fan EK, Liu J, Scott MJ, Li Y, Li S, Xie W, Billiar TR, Wilson MA, Jiang Y, Wang P, Fan J: Cold-inducible RNA-binding protein through TLR4 signaling induces mitochondrial DNA fragmentation and regulates macrophage cell death after trauma. Cell Death Dis 2017;8:e2775.

-31 Holdt LM, Thiery J, Breslow JL, Teupser D: Increased ADAM17 mRNA expression and activity is associated with atherosclerosis resistance in LDL-receptor deficient mice. Arterioscler Thromb Vasc Biol 2008;28:1097-1103.

32 Nicolaou A, Zhao Z, Northoff BH, Sass K, Herbst A, Kohlmaier A, Chalaris A, Wolfrum C, Weber C, Steffens S, Rose-John S, Teupser D, Holdt LM: Adam17 deficiency promotes atherosclerosis by enhanced TNFR2 signaling in mice. Arterioscler Thromb Vasc Biol 2017;37:247-257.

-33 Yan XX, Lu L, Peng WH, Wang LJ, Zhang Q, Zhang RY, Chen QJ, Shen WF: Increased serum HMGB1 level is associated with coronary artery disease in nondiabetic and type 2 diabetic patients. Atherosclerosis 2009;205:544-548.

-34 Chung HW, Lee SG, Kim H, Hong DJ, Chung JB, Stroncek D, Lim JB: Serum high mobility group box-1 (HMGB1) is closely associated with the clinical and pathologic features of gastric cancer. J Transl Med 2009;7:38.

-35 Lee H, Song M, Shin N, Shin CH, Min BS, Kim HS, Yoo JS, Kim H: Diagnostic significance of serum HMGB1 in colorectal carcinomas. PLoS One 2012; 7:e34318.

-36 Angus DC, Yang L, Kong L, Kellum JA, Delude RL, Tracey KJ, Weissfeld L, GenIMS Investigators: Circulating high-mobility group box 1 (HMGB1) concentrations are elevated in both uncomplicated pneumonia and pneumonia with severe sepsis. Crit Care Med 2007;35:1061-1067. 